\title{
Territorios configurados en el departamento de Ayacucho a inicios del siglo XX: las provincias "alejadas" y la alteridad indígena quechua
}

\author{
Territories configured in the Ayacucho department at the beginning of the twentieth century: the "remote" \\ provinces and the Quechua Indigenous otherness
}

\author{
Irma del Aguila \\ Universidad Peruana de Ciencias Aplicadas, Perú \\ pchuiagu@upc.edu.pe
}

\begin{abstract}
RESUMEN:
El artículo se propone examinar, desde el enfoque del territorio, los cambios que se produjeron en el departamento andino de Ayacucho a inicios del siglo XX. Se intenta complejizar el concepto desde las ciencias sociales con la introducción de las dimensiones simbólicas: Se conciben las provincias "alejadas" y las "próximas", respecto de un "centro" huamanguino. Circulan flujos económicos que articulan y desarticulan el territorio departamental y se imaginan "distancias" físicas y evolutivas que separan a esas provincias "alejadas" de la modernidad. Reflexiona, asimismo, sobre el ordenamiento social que suscribe un discurso racialista que configura un "territorio" de la alteridad. Ese "lugar" es, en realidad, un tiempo espacializado, donde moran los indígenas: un "atrás" en el tiempo y un espacio distinto del mundo contemporáneo.
\end{abstract}

Palabras Clave: Territorios, Ayacucho, Siglo XX, Indígenas, Racialización.

\section{AbstraCt:}

This article intends to examine, from the territory conceptual perspective, the changes operated in the Andean department of Ayacucho, at the beginning of the XX century. We propose to build up a more complex concept with the Social Sciences contribution, introducing symbolic dimensions, in which: The provinces are seen as the "far" and the "near" ones with respect to the Huamanga center; The economic flows produce articulations and disarticulations in the department territory and the imagined physical and evolutive "distances" separate the "far" provinces from Modernity. It also considers the social order that subscribes a racialist discourse in which a "territory" of the otherness is represented. This "place" is, in fact, a spatialized time, where the Indigenous people live: a "back" time and a place other than the contemporary world.

KEYWORDS: Territories, Ayacucho, 20th century, Indigenous people, Racialization.

\section{EL CONCEPTO DE TERRITORIO}

El territorio no está considerado como un mero entorno físico dentro de cuyos límites “pasan cosas”. El territorio, en tanto concepto teórico y perspectiva metodológica (Llanos-Hernández, 2010), no se restringe a la descripción del espacio geográfico -la hidrografía de los ríos, aguadas, puquiales, cochas o manantiales, la orografía de los cerros, desfiladeros, pedregales, cañones, etc.- sino que, fundamentalmente, se concibe como una formación que tiene lugar "en el espacio geográfico a partir de las diferentes relaciones sociales" (Fernandes 2006, p. 4). Que "pasen cosas" en el territorio alude a esa visión abarcadora del concepto, entendido desde la "interfaz entre sociedad, su historia y el medio natural”, señala Jong (2001, p. 42); es, entonces, el espacio de los procesos sociales. Y, en ese sentido, estudiar el territorio es también una empresa epistemológica.

La "geografía crítica" entiende el territorio como el locus de las relaciones del poder, con una historia y sus conflictos (Altschuler, 2013). Para entender ese espacio donde se despliegan múltiples actores, provistos de diferentes estrategias y racionalidades que en esas convergencias producen diferentes territorios, Fernandes 
(2008) propone tres órdenes de territorios. El primer territorio, y el más visible en su demarcación, es el jurisdiccional que ejerce el Estado, el de la gobernanza, y sobre el que existe una autoridad política directa, como componente indesligable de los Estados nacionales. El segundo territorio es el de los diferentes tipos de propiedades; el tercero es el espacio propiamente relacional.

El segundo territorio, de dimensión económica, se configura a partir de la lógica de reproducción y control de recursos con este fin. Los distintos tipos de propiedad, capitalista y no capitalista, dan lugar a distintas organizaciones del espacio. En él, tienen cabida las relaciones sociales de producción, los procesos de acumulación de capital, los usos determinados de tecnologías que intervienen sobre el paisaje, etc. Esos distintos tipos de propiedad que se materializan en el espacio llegan, eventualmente, a colisionar en disputas territoriales, en "luchas por territorios" (Souza Júnior, citado en Fernandes, 2008).

Para Fernandes, el tercer territorio es el espacio de lo relacional, a partir del carácter conflictual, intrínseco, del primer y del segundo territorio. Estos territorios se despliegan y se superponen de forma tangente o más sustantiva. De ahí que el análisis del territorio sea, en realidad, un análisis multiterritorial.

Es posible reconocer diversos territorios en el ámbito cotidiano de la vida social, de límites reconocibles, con prescindencia o no de una demarcación física: el vecindario, la cancha de fulbito en el barrio, la propia ciudad (más allá de los carteles que señalan los límites, existen representaciones más o menos compartidas de cuándo se "está" en la ciudad y cuándo se "deja" la ciudad), etc.

Los grupos humanos ocupamos espacios donde se configuran diversos territorios bajo lógicas que pueden resultar dispares, incluso antagónicas. Eventualmente, esos grupos pueden entrar en disputa por el control. La ruta del contrabando es un ejemplo paradigmático de un territorio con flujos económicos intensos que se enfrenta, con acciones encubiertas o incluso con contingentes armados, a los límites y regulaciones del territorio fronterizo demarcado por el Estado.

En definitiva, puede suceder que una lógica de ocupación del territorio, promovida desde el centro administrativo, encuentre resistencia en grupos humanos comprometidos con el apuntalamiento de otra lógica en despliegue desde los "márgenes" del departamento: es el caso que nos ocupa, en el departamento de Ayacucho. Se expondrá cómo el sur ayacuchano pugna por rearticular corredores que vinculen las punas con los alfalfales (cabezadas) y con la costa, con puertos que prolonguen las rutas a mercados nacionales e internacionales.

Y abordará cómo desde el centro administrativo huamanguino (la capital del departamento) se configura un territorio que es también un orden espacializado: se conciben las provincias "alejadas" y las "próximas". Asimismo, se imaginan las "distancias" físicas y morales que separan a esas provincias (y su gente) "alejadas" del progreso. El presente trabajo explora los sentidos de una territorialidad que se configura en las interacciones sociales y simbólicas que, "nutridos" de un discurso racialista y, de forma más amplia, de la mirada de Occidente de principios del siglo XX, propone un "espacio" de la alteridad. Ese "lugar" ontológico es, en realidad, un tiempo espacializado, donde moran los “indígenas": un "atrás” (el pasado figurado) y un espacio “alejado" (por fuera de la cotidianidad de sentido), bien distinto del mundo de los contemporáneos que sí participan de la vida nacional.

\section{AyACUCHO: PRIMERos APUNTES TERRITORIALES y ÉtNiCOS}

La mayor parte del territorio ayacuchano comprende punas y valles interandinos y, en segundo orden, ceja de selva y selva alta (Zapata, Rojas y Pereyra, 2008). La premisa de trabajo en este ensayo es que a esos disímiles territorios ayacuchanos que se configuran a principios del siglo XX en el espacio de las relaciones productivas y administrativas puestas en relación con el medio natural, se suma un tercer territorio, propio de lo relacional, donde se despliega un orden estamental, que con frecuencia se apoya con fines de soporte ideológico en los trazos cartográficos de la unidad administrativa. 
La fundación española de San Juan de la Frontera de Huamanga en 1539 obedece, nos recuerdan Zapata, Rojas y Pereyra (2008), al esfuerzo de asegurar el territorio recientemente conquistado: por un lado, contener a las tropas de Manco Inca, en rebelión contra la Corona de España, algunas de cuyas avanzadas se asentaban en el valle de Ninabamba, en lo que hoy es la provincia ayacuchana de La Mar; por otro, Huamanga era una ciudad intermedia en la larga y extenuante ruta que iba del Cusco, antigua capital del Imperio Inca, a Lima, la capital del nuevo virreinato. Nótese que el nombre fundacional da cuenta de la representación de un territorio fronterizo, que resiste el embate de los remanentes del ejército imperial inca en nombre de la civilización occidental y la fe católica.

Durante la Colonia, Huamanga encuentra gran parte de su sustento económico en la producción minera. Y, especialmente, en la mina de azogue de Huancavelica, de una importancia insoslayable: toda la plata del Alto y del Bajo Perú era amalgamada con ese mercurio (Zapata, Rojas y Pereyra, 2008). Esos tiempos de bonanza se asociaron a la ciudad Huamanga, por su peso administrativo y sus vínculos comerciales con Huancavelica. En el siglo XIX, la mina de azogue, que conoció su época de mayor producción en los siglos XVI y XVII, entró en un total abandono (Contreras y Díaz, 2008). Con la República, el departamento de Ayacucho entró en un periodo de declive económico, de franco enclaustramiento, señalan Zapata, Rojas y Pereyra, "debido a que al interior de este espacio no se consolidó una especialización productiva" (2008).

Desde su creación republicana en 1822, e incluso antes, es posible identificar una permanente tensión entre la demarcación territorial estatal administrativa, en cuyo centro se encuentra la ciudad de Huamanga, ${ }^{1}$ y diversos territorios ayacuchanos que describen circuitos económicos centrífugos, sobre todo comerciales, siguiendo las rutas coloniales e incluso prehispánicas. Un camino muy frecuentado sigue en gran parte el antiguo trazo del Qapaq Ñan inca ("Gran Camino", en quechua) y, como se ha comentado más arriba, pasa por Huamanga en la larga ruta que iba del Cusco a Lima. Desde el siglo XIX, en las provincias sureñas de Parinacochas y Lucanas, se asientan caminos de arrieros que vinculan los fértiles pastizales, las denominadas "cabezadas" para el engorde de ganado vacuno y de auquénidos, con los valles yunga de la costa. Se profundizará una progresiva desarticulación del espacio departamental, tal como estaba delimitado por la administración estatal. En estas rutas de arrieros se producen intensos intercambios materiales y simbólicos (hábitos de consumo, encuentros en ferias, lazos de compadrazgo, etc.) al amparo del comercio de la lana y del ganado.

A principios del siglo XX, las mayores haciendas, en manos de terratenientes y gamonales, ${ }^{2}$ se concentraban en el norte y centro, en las provincias de Huamanga, Huanta, Cangallo y Andaluaylas (Zapata, Rojas y Pereyra, 2008; Pereyra, 2019; Glave y Urrutia, 2000), ocupando diferentes pisos altitudinales (del Pino, 2017); en ellas, predominaba el denominado sistema de hacienda, ${ }^{3}$ que se apoyaba en relaciones de trabajo servil y pongaje 4 "indígena", 5 que coexistían con el sistema de peonaje (Zapata, Rojas y Pereyra, 2008). Zapata, Rojas y Pereyra sostienen que en Ayacucho no se produjo una concentración agresiva de la gran propiedad. Las haciendas eran, en su mayoría, pequeñas o medianas (2008). Del Pino señala que, a diferencia de lo que ocurría entonces en los departamentos surandinos de Arequipa y Puno, donde sí se expandió la hacienda como consecuencia de la penetración del capital mercantil de la lana, en Ayacucho "no llegaron a capitalizarse ni a mejorar la infraestructura productiva" (2017, p. 167), y se produjo, más bien, una rearcaización de las relaciones sociales y laborales.

En las provincias de Parinacochas y Lucanas son contadas las medianas propiedades agrícolas, concentradas principalmente en Coracora, Pausa y Lampa (Pereyra, 2019; Monografía de la provincia de Parinacochas, 1950); dominaban, más bien, las tierras comunales "indígenas" y los hatos y estancias de pequeños campesinos. En Parinacochas, refiere Dagoberto Choque (2018), desde fines del siglo XIX la élite de "mistis"6 (hacendados y comerciantes "blancos" o "mestizos") convivía, en términos no exentos de tensiones, con campesinos "indígenas" que se beneficiaban del comercio de la lana de alpaca y oveja -en tanto arrieros, arreadores, "alcanzadores", comerciantes al menudeo, artesanos, etc.- y, posteriormente, de la 
cría y venta del ganado vacuno. El sur ayacuchano "siempre fue un refugio de las comunidades campesinas", sentencian Zapata, Rojas y Pereyra (2008).

La realidad étnica en el Ayacucho de principios del siglo XX merece un primer apunte. En el Censo Nacional de 1940 (INEI, 1944) se consigna que la población de "raza india" en el departamento era abrumadoramente mayoritaria. Es de destacar que la categoría "raza india" enunciada por el Estado peruano remite a la sociedad de castas de la época colonial todavía habitual en el léxico republicano del siglo XIX y, como se aprecia, de la primera mitad del siglo XX. El término "indio" está insoslayablemente cargado de discriminación histórica y de connotaciones despectivas.

Nombrar quién es qué es un ejercicio de poder. A principios del siglo XX, la "raza” estructuraba, aunque no agotaba, las relaciones sociales en el Perú y, todavía más, en el sur andino, donde prevalecía el sistema de hacienda en permanente tensión con las tierras comunales "indígenas". En el trazado de las fronteras étnicas se despliegan, siguiendo al sociólogo Andreas Wimmer (2008), tanto categorías étnicas como sociales o conductuales. Es decir, en la sociedad peruana, el campo semántico que se abre es el resultado de luchas de clasificación del "otro" y también de negociaciones permanentes en el ámbito de las estructuras de poder y de las redes sociales que entran en juego. Como veremos en este artículo, no se trata pues de delimitaciones fijas ni unívocas, sino, antes bien, de trazos fundamentalmente contingentes, porosos y relacionales en los que se involucra lo fenotípico pero también lo étnico, la cultura, la posición de clase, el género, etc. Se propone, además, que el tipo de tenencia de la tierra configura un tipo de territorialidad atravesada y la vez demarcadora de límites étnicos, y en permanente disputa en el sur andino.

Complejizando la construcción fronteriza de lo étnico, se postula en este trabajo que el concepto "indígena" (y no "indio") funciona parcialmente como un hiperónimo (Silva, 2021), es decir: alude a campos semánticos necesariamente heterogéneos y densos. Los términos que hacen de hipónimos (por ejemplo, "quechua", "aimara", "shipibo conibo", etc.) entran mas no se agotan, ya que añaden otros rasgos semánticos que rebasan lo "indígena”. Así pues, se sostiene, de forma preliminar, que lo quechua que "cae" dentro de la categoría taxonómica "indígena" puede desbordar, de forma contingente, lo étnico, y podría afirmarse, al mismo tiempo y no sin ambigüedades, como "pueblo" o incluso "mestizo".

Volviendo al Censo Nacional de 1940, el Estado peruano emplea en la identificación de lo "indio" indicadores culturales: el criterio identitario (que determina quién es "blanco", "mestizo", "indio") es, principalmente, el dominio de la lengua originaria o el de la castellana. Así, pues, lo étnico se culturaliza, pero sólo en apariencia. A despecho de la retórica estatal, se puede asumir que la lengua es un indicador, entre otros, que entran a tallar en la delimitación de la frontera étnica de las sociedades surandinas de principios del siglo XX; y que la "raza" (lo biológico y, sobre todo, el fenotipo) no desaparece, sino que impone una presencia más o menos implícita. Quedémonos, por el momento, con las cifras del Censo de 1940: de los 299.769 habitantes del departamento de Ayacucho, 246.947 sólo hablaban la lengua quechua, 49.942 el castellano y el quechua, y los castellanohablantes eran una élite minoritaria: apenas 2573.

\section{Carreteras, ¿Desarticulación del territorio?}

En el departamento de Ayacucho, la autoridad estatal se enuncia desde una posición de "centro" político y geográfico -la capital- y también simbólico, el centro del espacio imaginado. El sistema de referencia cartesiano, construido por el Estado peruano, desde una distancia tecnológica y a partir de decisiones administrativas ajenas a las comunidades involucradas en el ordenamiento, propone entre los pobladores una mirada cartográfica subjetiva que orienta la experiencia cotidiana del espacio (Blanco, 2007). Los que moran dentro de los límites viven y se reconocen en tanto "ayacuchanos". El destino común se formula en términos de lo adscripto a un espacio y a un tiempo continuos.

Por un lado, se reconoce un territorio "tangible"; del otro, una línea de tiempo que se proyecta hacia un pasado imaginado, vale decir, un "atrás", que sería el tiempo prehispánico que, ya para entonces -con 
las investigaciones arqueológicas de Alberto Arca Parró (1923), Víctor Navarro del Águila (1939) y, sobre todo, con las excavaciones emprendidas por Julio C. Tello en 1942 y en adelante-, se representa "milenario", ocupado por los waris, pokras, chankas (Arroyo, 2003) y otros pueblos preincas. Ese territorio se proyecta también el futuro, que sería lo que resta por hacer y que se tiene "adelante". Hay que advertir, sin embargo, que los ayacuchanos de principios del siglo XX, étnica, cultural y socialmente tan disímiles, no se reconocen en un plano de convivencia horizontal ni de contemporaneidad, como veremos luego. ${ }^{7}$

El Oncenio del presidente Augusto B. Leguía (1919-1930) da un impulso mayor a las obras de infraestructura y, sobre todo, a los proyectos viales, dentro de una retórica política que anuncia la Patria Nueva (Drinot, 2018). El ferrocarril y las carreteras se construyen al amparo de la Ley de conscripción vial que, en los hechos, era trabajo forzado "indígena" y que revivía en cierta forma la institución colonial de la mita (Gonza, 2020). Por ello, no deja de ser paradójica la imagen de la inauguración de la carretera La Mejorada-Huamanga, en 1924 (Glave y Urrutia, 2000), que coincide con las celebraciones por el centenario de la batalla de Ayacucho, que selló la independencia de América del "yugo español".

Esas obras viales de gran envergadura son vistas por los ayacuchanos bajo un prisma ambivalente: por un lado, la infraestructura vial y los medios de comunicación masivos que irrumpen con la esperanza de la modernización en la vida social (en los que se destacan la radio y los diarios de circulación nacional), en fin, las expectativas que suscitaba la promesa del "progreso"; y, por otro, son rutas que "abren" el departamento a un espacio de articulación más denso y vasto que se realizará en detrimento de un centro regional. En ese sentido, la carretera La Mejorada destrona a la capital ayacuchana en el rol de articulador de los flujos comerciales hacia Lima y, más bien, acentúa una subordinación a la pujante ciudad de Huancayo.

Asimismo, impacta dramáticamente en los pequeños comercios locales y haciendas de las provincias del norte, que no pueden competir con los precios ni con el volumen de comercialización de los mayoristas de Lima y Huancayo; amenaza la existencia de los arrieros y los circuitos que estos describen a su paso por la difícil geografía, así como las relaciones comerciales y sociales (incluso de parentesco y compadrazgo) que entablan en el territorio. El obispo de Huamanga, Fidel Olivas, describe así el devastador impacto social y económico que acarreó la construcción de la carretera La Mejorada-Huamanga:

"Sus industrias han ido languideciendo, y puede decirse, que han desaparecido; por no haber podido sostener la competencia con los artículos similares extranjeros; la ciudad se despuebla porque sus hijos emigran a buscar en otras partes donde emplear con ventaja la inteligencia y laboriosidad de que están dotados; siendo el resultado de este cuadro desconsolador, la indigencia y los vicios que son su forzoso cortejo. (Rojas, 2010, p. 31).

A La Mejorada se sumó, en 1926, la carretera Puquio-Nazca, un tramo importante por ser una vía de salida del sur ayacuchano a las costas de los departamentos de Ica y Arequipa. La sensación de "pérdida” de la "unidad territorial" alude al menor peso integrador del centro administrativo del departamento, como consecuencia de dinámicas comerciales centrífugas.

"La carretera, considerada un medio de integración, en este caso se había convertido en un medio de desintegración y con ella Ayacucho perdía su integridad como región económica, en adelante sólo quedará su influencia política, aunque también debilitado" (Rojas, 2010, p. 22).

Coracora, pujante ciudad de la provincia de Parinacochas, conoce un auge comercial desde fines del siglo XIX por su ubicación estratégica para el comercio de ovinos y lanar, en medio de un corredor ecológico que “empezaba en las punas de Lucanas, Parinacochas y Andahuaylas y finalizaba en las cabezadas" (Pereyra, 2019, p. 104) de los valles costeños, donde se cultivaba la alfalfa para el engorde del ganado, antes de su embarque en los puertos de Chala o Lomas. El siguiente mapa muestra la relación directa entre pisos ecológicos (líneas negras diagonales) y algunas rutas de circulación de la lana y del ganado vacuno (flechas rojas). Se incluye una ruta alterna (flechas azules) para el comercio de lana de alpaca, por el cañón de Cotahuasi, en dirección a la ciudad de Arequipa. 
Figura 1. Franjas ecológicas en el territorio ayacuchano y rutas del ganado vacuno

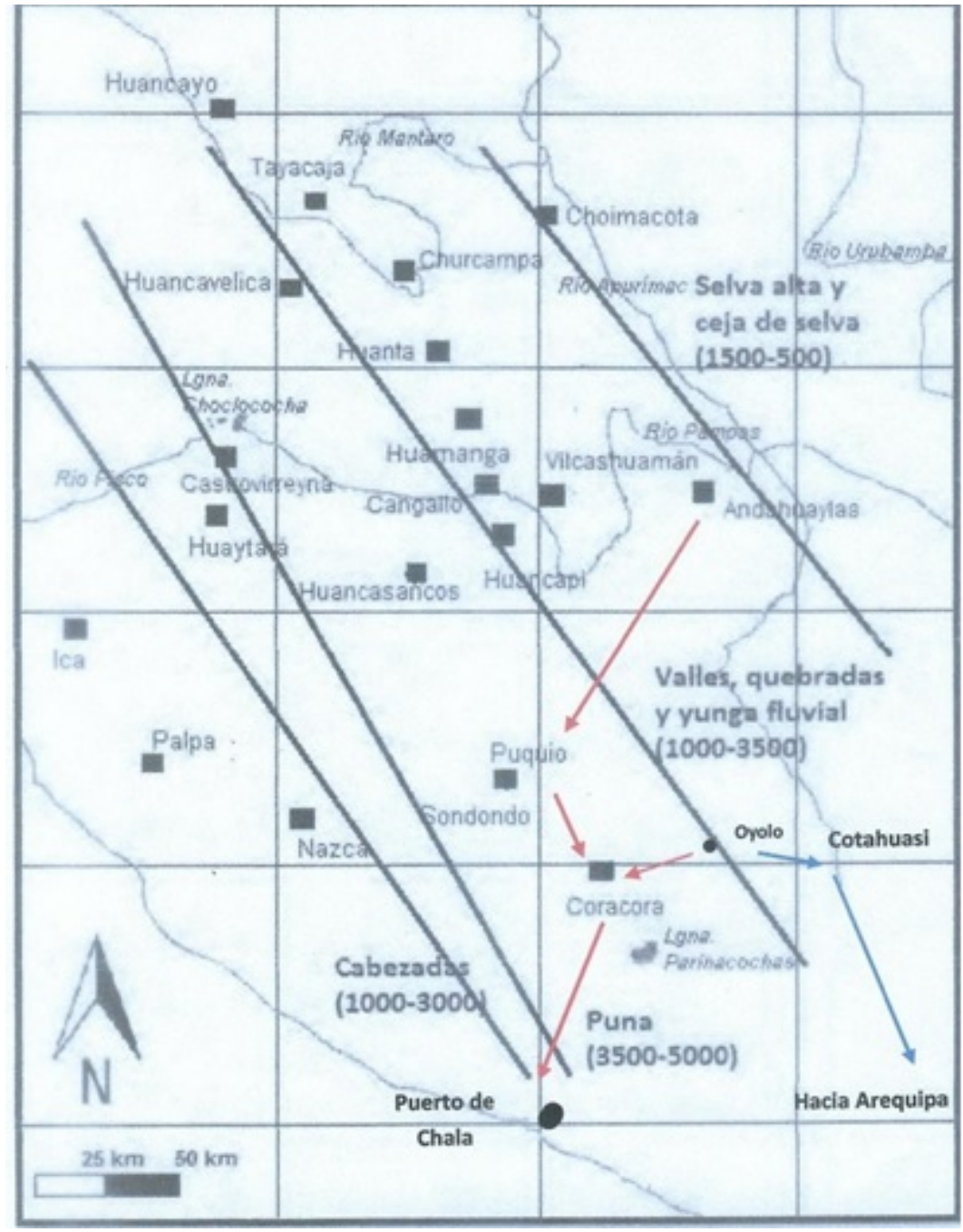

Elaboración propia, a partir del mapa de pisos ecológicos en Pereyra (2019)

En el proceso de rearticulación económica del territorio ayacuchano se identifican fuerzas exógenas, Lima, la capital de la República y la ciudad de Huancayo, pero también los puertos de Pisco en Ica y de Chala y Lomas en el departamento de Arequipa, además de la propia ciudad de Arequipa.

Así, el debilitamiento del peso del centro huamanguino en los años 1920 y 1930 se manifiesta en la agudización de un proceso que es su contraparte: una rearticulación del espacio departamental. Se reconoce la intervención de las fuerzas del capital y el imperativo de la reproducción de este en el apuntalamiento de esos flujos económicos exógenos que descentran el territorio político y administrativo.

En consonancia con este proceso, queda manifiesta la intervención del centralismo limeño como la fuerza mediadora del capital financiero y comercial. Lima y el gran capital son acechanzas concretas que encuentran eco en grupos de poder local, llevados por el beneficio y la ilusión de la modernidad. "Mientras la construcción del ferrocarril y la carretera respondían más a la política del gobierno central, aunque ello no ha limitado la participación de miembros del grupo de poder local exigiendo su realización bajo la gran esperanza de progreso y cambio para Ayacucho" (Rojas, 2010, p. 3).

Sin desmedro del entusiasmo que despertaba en los ayacuchanos esa promesa de modernidad y de ansiada transformación en el departamento, apuntalada por la revolución en los medios de transporte, es necesario descentrar la mirada para identificar las apuestas políticas que se van materializando en las territorialidades del sur, en su pugna por salir de los "márgenes" del poder huamanguino. 
Los vecinos "notables" de Coracora (hacendados y comerciantes) gestionarán por años y obtendrán finalmente del Congreso de la República su designación como nueva capital provincial, en 1891, en detrimento del apacible poblado de Pauza (Canales y Franco, 2019). No satisfechos con este triunfo político, los coracoreños pretenderán sin éxito desligarse de Huamanga, mediante un intenso cabildeo en la capital de la República en el afán por plasmar un viejo proyecto político: la creación del departamento de los Andes (Canales y Franco, 2019).

\section{EL CENTRO Y LA PERIFERIA}

El primer territorio, nos recuerda Fernandes, es el espacio de gobernanza de la nación (2008). En ese sentido, las prácticas del poder estatal sobre el territorio se plasman en lo que Ferguson y Gupta llaman la “espacialización” del Estado (2002). El sistema de referencia cartográfico es un instrumento que sirve tanto para representar un orden como para administrarlo y, de ser preciso, imponerlo.

En este sistema, las localidades -ciudades, pueblos, caseríos, anexos, etc.- se representan en mapas de superficie plana, que resultan de la intersección de meridianos y longitudes. Pero la localización en los mapas es más que un ejercicio de distribución espacial: esa localización es ya un orden propuesto. El Estado establece una jerarquía en el plano cartográfico entre la sede central y sus dependencias, en la cual las autoridades y funcionarios son destacados en la extensión del plano en posiciones claramente escalonadas en la administración pública (por ejemplo, prefecto, subprefecto) y en la que la asignación de las partidas presupuestarias también varía entre niveles de gobierno (departamento, provincia, distrito, etc.). Por lo demás, los mapas viales van configurando una red que converge en un centro, el "kilómetro 0" referencial. El espacio así demarcado queda, de forma inevitable, signado por una mirada social: lo que está "cerca" y lo que está "lejos" del poder huamanguino. Rojas destaca una nota publicada en el periódico huamanguino El Heraldo del 18 de enero de 1932, que apoya la ejecución del proyecto vial Huamanga-Puquio (provincia de Lucanas), obra "muy necesaria y reclamada, tanto para ponerse la capital departamental en contacto inmediato con sus provincias alejadas ${ }^{8}$ cuanto porque reportaría a esta ciudad, Huanta, San Miguel y otros, una utilidad, intercambio de productos..." (citado en 2010, p. 145). ${ }^{9}$

Las carreteras y redes ferroviarias dan cuenta de una racionalidad distributiva de la administración pública y del capital. En el caso que se comenta, la carretera es un bien asignado de forma discriminada, siguiendo criterios geográficos, demográficos, pero también políticos y estratégicos definidos desde centros administrativos y comerciales (Huamanga, Lima, Huancayo, etc.), que establecen sus prioridades en función de su visión de progreso, su capacidad y vocación de articulación, y de una lógica territorial de reproducción del capital.

Desde Huamanga, en el norte, las provincias sureñas de Lucanas y Parinacochas se ven "alejadas", y lo son, si nos atenemos a las pobres redes de integración física. La cartografía expone esas provincias en los márgenes del sistema administrativo y vial. Pero ese orden transmite también una experiencia de lo "alejado" que es aquel espacio "desprovisto" de una infraestructura moderna y, a final de cuentas, de la experiencia de modernidad.

\section{EL PRESENTE Y EL PASADO}

El discurso antropológico del siglo XIX y de comienzos del siglo XX enuncia un "otro" no occidental (para el caso, el "indígena" quechua) y lo ubica en un "lugar" donde el tiempo se espacializa: un horizonte particular pues, a contracorriente del trabajo etnográfico realizado desde un "ahora", anota Johannes Fabian (2014), la tradición antropológica ubica a esos no occidentales por "fuera" del mundo de los contemporáneos.

Esa retórica es una mirada occidental de la alteridad que va a permear los discursos racialistas a lo largo del siglo XIX y comienzos del siglo XX, cuando se exacerba esta dimensión de una "alteridad" desterrada. 
Sus antecedentes inmediatos se encuentran en el siglo XVIII. La Ilustración traza mapas de la geografía humana, en los que el carácter y el humor de los pueblos (los mediterráneos, los africanos, los escandinavos, los insulares, etc.) están signados por el paisaje, el relieve y el clima de los ecosistemas. El filósofo Charles Montesquieu escribía en El espíritu de las leyes, publicado en la ciudad de Ginebra, en 1748: "Si es una verdad que el carácter del genio y las pasiones del corazón son absolutamente distintas en los diferentes climas, las leyes deberán acomodarse a sus diferencias" (2018, p. 235). Montesquieu asigna trazos morales que distinguen a los pueblos de clima caliente, propensos a la pereza y al apocamiento, de los pueblos de clima frío, inteligentes, arrojados y honestos: "Los pueblos de los países cálidos son tan tímidos como los ancianos y los de los países fríos, valientes como los jóvenes” (2018, p. 236).

Desde mediados del siglo XIX, el racialismo científico se impondrá como corriente de pensamiento más allá de Europa, entre las élites de sociedades coloniales o poscoloniales. Los ensayos de Arthur Gobineau, Ernest Renan y, sobre todo, del sociólogo positivista y psicólogo Gustave Le Bon serán populares entre los intelectuales peruanos (Obregón, 2019). Le Bon, en Las leyes psicológicas de la evolución de los pueblos, publicada en 1894, introduce el concepto de "alma colectiva", que es el carácter moral e intelectual de un pueblo, una síntesis "de todo su pasado, la herencia de los ancestros, los móviles de su conducta" (1895, p. 17).

Le Bon presenta un orden taxonómico que propone un nivel de desarrollo de las "razas": las primitivas, que sobreviven en estado de animalidad (por ejemplo, los fueguinos); las inferiores, sumidas en la barbarie, aunque cultivan ciertos "rudimentos de civilización" (negros); las medias (chinos, semitas); finalmente, las superiores, los indoeuropeos, pueblos de mayor desarrollo civilizatorio, herederos de las grandes culturas griega y romana (Obregón, 2019). Inútil destacar la influencia del darwinismo social, una tesis que extrapola arbitrariamente premisas del mundo orgánico y de la selección natural de las especies al orden social, con sociedades "superiores" e "inferiores" en el proceso evolutivo, que no es otro que el representado desde la civilización occidental.

Tampoco se puede soslayar en estos autores franceses y en otros europeos su aquiescencia a proyectos coloniales. Arthur Gobineau en su Ensayo sobre la desigualdad de las razas humanas y Ernest Renan en La reforma intelectual y moral suscriben un orden imperial que se ejerce sobre todo en África y Asia. El mandato civilizatorio europeo queda así legitimado: "una raza de trabajadores de la tierra, es el negro; sed para él bueno y humano, y todo estará en orden; una raza de amos y soldados es la raza europea [...] Que cada quien haga para lo que está hecho y todo irá bien" (Renan, 1871, p. 94).

Le Bon, sin embargo, establece un matiz: los estadios de desarrollo de las "razas" serían el resultado de circunstancias históricas y culturales tanto como de inconmovibles factores biológicos (Dantier, 2002, p. 5). Aunque, advierte, los rasgos psicológicos adquiridos "no se transforman sino luego de la acumulación de tiempos" (Le Bon, 1895 , p. 142). Por lo tanto, son casi ${ }^{10}$ tan fijos como los caracteres físicos.

En el Perú de fines del siglo XIX, los intelectuales de la llamada "segunda escolástica” en la Universidad de San Marcos y, posteriormente, el historiador y filósofo positivista Javier Prado, van a suscribir en un primer momento un racialismo influenciado por la premisa naturalista que coloca las "fuerzas de la naturaleza" (Obregón, 2019, p. 5) como las constituyentes del carácter de los pueblos, evocando inevitablemente la filosofía ilustrada de Montesquieu del siglo XVIII y de Germaine de Staël, de inicios del siglo XIX, en franco retroceso en Europa. En el discurso inaugural del año académico de 1894 en la Universidad de San Marcos, Prado destaca el lugar que tiene el clima en el modelamiento del carácter de los pueblos: "La temperatura general del Perú, por su posición geográfica, es la de los países meridionales, y bajo la influencia inmediata del sol, la raza es física y moralmente débil [...] De ahí ser la pereza un vicio inherente a los habitantes de estos climas" (Obregón, 2019, p. 5).

La generación de Jorge Polar (1856-1932) y la posterior, de Javier Prado (1871-1921) y Clemente Palma (1872-1946), estuvieron marcadas por la desastrosa guerra con Chile (1879-1883). El discurso racialista busca en buena medida explicar el fracaso de los proyectos nacionales. Prado suscribe el razonamiento leboniano que clasifica las "razas" para el Perú, los blancos, los indios y los negros, y un amplio abanico 
de mezclas: mulatos, mestizos, zambos, entre otras, dentro de un orden de jerarquías morales, y les adscribe una suerte de "males" que imprimen al conjunto de la sociedad peruana (Obregón, 2019). El académico arequipeño Jorge Polar, por su parte, "veía en el atraso del país 'un problema de nuestra raza enferma'" (citado en del Águila, 2013, p. 238), la "indígena”. Tanto Polar como Prado asumen premisas racialistas y, sin embargo, vislumbran miradas "culturalistas" que les permiten ir más allá de las premisas del determinismo biológico. Si Polar confía en superar la "enfermedad" que aqueja a los "indígenas", Javier Prado y otros positivistas van a desarrollar una visión de progreso apoyada en las "virtudes" de las "razas superiores" (población de origen europeo), que cultivan el amor a la libertad y la capacidad de industria. Plantean "renovar" la raza y la herencia de dos formas: por la eugenesia, fomentando la migración europea, y por la educación, "elevando el carácter moral” (Obregón, 2019, p. 12) de los pueblos.

Esta visión "regeneradora" no es unánime. Clemente Palma ve en el "indio" a una "raza degenerada"; su debilidad moral e intelectual, argumenta, permanece insensible incluso ante el estímulo de la educación: "Tiene todos los caracteres de la decrepitud y la inepcia para la vida civilizada" (1897, p. 15).

De la Cadena sostiene que el concepto de "raza” en América Latina, "como en el resto del mundo, [...] emergió posibilitada por ambos discursos (el de biología y el de cultura) pero que en nuestra región la tendencia ${ }^{11}$ fue discutirla (y, por tanto, producirla) en el campo de la cultura" (2004, p. 14). Hay una fe positivista de Prado y Polar en el progreso científico y un afán por relativizar el componente biológico. De la Cadena (2004) destaca la tensión dialógica que las élites peruanas y latinoamericanas sostienen con las de Occidente (Europa, Estados Unidos), por imponer sus proyectos nacionales, de progreso y civilización, $a$ pesar ${ }^{12}$ de sus orígenes y rasgos fenotípicos, no siempre "blancos".

¿Cómo se traslapa esta condición de deterioro agónico del "ser indígena” con la ocupación del territorio? Una primera observación de la lectura de los escritos de las élites limeñas y andinas es el sentido ontológico que adquiere el espacio. Se va a subrayar en la descripción del paisaje social una "raza indígena" instalada naturalmente en un locus geográfico. José Carlos Mariátegui hace eco de un sentido común enraizado en su tiempo: los "indígenas" moran y resisten, culturalmente hablando, en un hábitat que es también un lugar en la historia y en el "alma” nacional: "la sierra es indígena; la costa es española o mestiza” (2007, p. 205). La colonia ha desterrado a los "indígenas" de los valles y arenas de la costa: "la raza y la lengua indígenas, desalojadas de la costa por la gente y la lengua españolas, aparecen hurañamente refugiadas en la sierra” (Mariátegui, 2007, p. 206). En el sur andino se mantiene todavía "una vieja unidad: la heredada de los tiempos de la civilización inkaica. En el sur, la 'región' reposa sólidamente en la piedra histórica” (2007, p. 208).

Esos "indígenas" son con frecuencia descritos como seres sometidos a la inclemencia del clima en las alturas de la puna. Estos puntos geográficos son vistos en su "lejanía”, que es física respecto de la capital ayacuchana (o de la república) y refractarios al anhelo de progreso. Pero también inspiran sentimientos adversos (se destaca su condición agreste). En otros casos, se trata de una "raza" atrapada en un pasado de oprobio y explotación colonial que marca su vida en el tiempo presente. En ambos casos, la "redención" del indígena", se postula en el presente trabajo, será concebida por las élites como un viaje físico y moral. Ese tránsito se iniciaría en un "lejano" punto del paisaje, que es también de atraso, hacia un punto más "cercano" respecto del que enuncia, vale decir, hacia un futuro que es de progreso, en una representación de "evolución” lineal de la historia: el tiempo suspendido queda así espacializado.

En consonancia con este discurso, Rojas destaca en su tesis un comentario que sobre los "indígenas" emite el ingeniero José R. Ruiz Fowler en su "Monografía Histórico-Geográfica del departamento de Ayacucho", publicada en 1924:

\footnotetext{
"Raza valiente y sufrida; indolentes por temperamento los que habitan las soledades de la puna tienen por ocupación la vida pastoril y el cultivo empírico de sus vastas tierras. En la proximidad a las poblaciones y cerca al clima templado de los valles, son más aspirantes: buscan la vida independiente en el arrieraje, el pequeño comercio y en las artes propias" (citado en 2010, p. 41).
} 
A partir de un sistema de estratificación del relieve de los suelos se construye un imaginario bien cimentado entre las élites: en el valle, bendecido por llanuras y por un clima templado, florece la agricultura; es el espacio donde se asientan las ciudades y centros administrativos con poblaciones extensas. Ahí prosperan el comercio, la cultura letrada, las artes; en definitiva, la "civilización". En contraste, es la puna un entorno de "soledades", naturalmente agreste para la reproducción de la vida. El paisaje de la puna se puebla de "cultivos empíricos" y del pastoreo; esta última, actividad trashumante; en esas alturas, se instalan asentamientos humanos dispersos en la geografía que albergan a grupos reducidos de pobladores, vinculados con lazos de parentesco. Siguiendo nuevamente al ingeniero Ruiz Fowler, miembro de la Sociedad Geográfica de Lima:

\footnotetext{
"Mientras el indio de las punas solitarias y sin paisaje, es triste, hosco y huraño; el de las quebradas esalegre, franco y amigable. En los primeros el sentimiento de lo bello no existe y en los segundos, que fueronlos que estuvieron en contacto con los españoles, tienen en su cerebro el sello de su origen, son ardientes,turbulentos y soñadores. El tipo huamanguino [es decir de la capital de Ayacucho], el de los valles de Huanta,el de Cangalla [sic] y los de las quebradas de Parinacochas y Lucanas, son ejemplos de asimilación a esa nobleraza española" (citado en Rojas, 2010, p. 39).
}

En consonancia con el discurso positivista, los "indígenas" quechuahablantes de los valles huamanguinos, huantinos y cangallinos y de las quebradas de las provincias del sur se "beneficiarían" del contacto físico y cultural con la "raza española", que transmite, se sostiene, la alegría por la vida, el ardor y el empuje, necesarios para realizar emprendimientos. En definitiva, los pisos altitudinales dominantes en el departamento de Ayacucho, la puna, la quebrada, los valles, la yunga fluvial, la selva alta y la ceja de selva son espacios que signan una ecología humana y son, además, espacios revestidos de sentidos simbólicos que hablan de la condición del "indígena", de su pretendido atraso, y emiten un relato etiológico para entender el origen de dicha postergación. El peso de la historia de sometimiento y explotación, el "encierro" en un hábitat físico y moralmente "malsano" devienen en elementos discursivos que legitiman la presencia de las élites no "indígenas" en el territorio y les otorgan una misión de redención.

Enfatizamos que la escisión imaginada entre, por un lado, los "indígenas" que moran en las punas y, por otro, los criollos, mestizos y los "indígenas" culturalmente "asimilados" de las quebradas y valles, es pretendidamente civilizatoria y espacial. Fabian discute cómo la antropología convierte las diferencias étnicas y culturales en un distanciamiento espacial y temporal insalvable (2014) entre pueblos no occidentales y occidentales, negándoseles a los primeros la condición de coetáneos de los segundos.

Desde el primer tercio del siglo XIX, se impone en Occidente un tiempo abstracto (Fabian, 2014), que prescinde del contexto ritual y subjetivo y es, por tanto, un tiempo que se seculariza, que es ya una forma de ocupar el espacio, en la medida en que organiza la experiencia humana a lo largo de una linealidad temporal. Todavía más: ese tiempo coloniza el espacio así dispuesto, dotándolo de un sentido pretendidamente "natural". Fabian comenta que la antropología, para llevar a cabo la empresa epistemológica que consagra la diferencia cultural y moral como distancia -entendiendo por distancia aquello que sólo el progreso puede superar en una apuesta a futuro-, en un símil con la Historia natural se concibe inmersa en la espacialidad del tiempo. Así, el tiempo geológico es mesurable en unidades cronoestratigráficas que son cuerpos de roca donde se configuran los pisos. En pocas palabras, los procesos formativos de la Tierra (tiempo) se exponen espacialmente (pisos).

Esa empresa cognitiva trasvasa de la Historia natural unas "leyes naturales", marcadas por la impronta evolucionista. Así, en el siglo XIX, marcos teóricos de interpretación de la realidad social y económica "ubican" y distancian las sociedades en el tiempo y en el espacio. El marxismo, entre otros, expone una interpretación materialista de la evolución histórica de las sociedades que culmina en Occidente con la Revolución Industrial, que expone un desarrollo culminante de las fuerzas productivas y de las relaciones sociales de producción e irrumpe en el Imperialismo, fase superior del capitalismo. Muy por "detrás" de la ruta hacia la modernidad del capital quedan otras formas de organización societal y económica. El pastoreo, desde las perspectivas de la antropología evolutiva y del pensamiento marxista, no es sino un "momento" 
liminar en el proceso civilizatorio. Uno en el que los medios de subsistencia y de acumulación de excedentes son precarios.

Pero los "indígenas" no solo eran pastores y agricultores “empíricos” instalados en las alturas y en los valles y quebradas. Unos otros "indígenas” que engrosan la población de las villas y ciudades ayacuchanas también son vistos desde una mirada "lejana", marcada por la distancia social pero, también, por una temporalidad suspendida. Rojas retiene una cita de Alayza y Paz Soldán del año 1940:

\footnotetext{
"Una enorme mayoría (de habitantes de la ciudad) es de indígenas analfabetos representativos de pueblos milenarios, ${ }^{13}$ que no se renuevan y donde, por lo tanto, la ignorancia es un bloque impermeable y las supersticiones se estratifican [...] carece de industria y no vale la pena tomar en cuenta la de los afamados trabajadores en piedra de Huamanga, plata, cuero, y madera, pues la miseria del lugar obligolos a emigrar a Lima apenas estuvo abierta la carretera de la muerte [...] el comercio, a juzgar por los establecimientos de la ciudad, es insignificante y su mayor renglón es el del alcohol y la coca, artículos que se exhiben a las puertas de los tenduchos atrayendo a los indios como imán al hierro" (citado en 2010, p. 40).
}

Esos pueblos "milenarios" parecen atrapados en el pasado, pues "no se renuevan”. Más aún, los "indígenas" mantendrían un mundo de creencias atávicas, las "supersticiones" que son propias de los antepasados. La condición "impermeable" de los “indígenas analfabetos” se racializa. Así, para respaldar esta imagen de seres estancados en el tiempo se expone una situación que explicaría la degeneración de la "raza indígena" puesta en contacto con la civilización occidental: la indolencia, la ignorancia y el embrutecimiento por el consumo persistente y excesivo de la coca y el alcohol, desde los tiempos coloniales. De este modo, aunque esos "indígenas" comparten en las ciudades espacios de interacción con la "raza española" y criollos, y son "más aspirantes" que los "indígenas" de las punas, viven en horizontes temporales que se encuentran en permanente tensión, entre un pasado que tendrían definitivamente que dejar "atrás" y el presente, al que deberían aspirar. Fabian señala que los "otros" sujetos ("indígenas" americanos, negros de las costas africanas, del Caribe, etc.), distintos de los "unos" de Occidente, no se mueven en un espacio "pleno" de realizaciones humanas, que es el aquí y ahora, sino en un tiempo "pendiente" (2014). O, en palabras de E. Hirsch en su análisis del texto de Fabian, "los grupos que son percibidos como 'primitivos' por los 'civilizados', aunque viven en el mismo tiempo, en el mismo 'ahora' [...] son vestigios antiguos, salvajes o bárbaros, ubicados en otra zona temporal, como 'antepasados contemporáneos'” (2008, p. 22).

La visión de la "degeneración" moral y cognitiva de los pueblos originarios se mantiene, como vemos, entre las élites limeñas y andinas, incluso hasta bien entrado el siglo XX. Y respalda la persistente oposición a la incorporación de los "indígenas" a la vida ciudadana, en términos de horizontalidad. ${ }^{14}$ Con frecuencia, las élites se apoyan en los diagnósticos cientificistas impregnados de racializaciones publicados en las primeras décadas del siglo XX: el médico huanuqueño Hermilio Valdizán, explica por factores históricos, particularmente la hecatombe de la conquista y el yugo colonial, el "agotamiento brusco" de la raza (1924, p. 160).

Intelectuales peruanos radicales van a cuestionar este cimiento etiológico del racialismo: la idea de "degeneración” del indio. Se destaca la figura del anarquista Manuel González Prada, quien en "Nuestros indios" expone a la crítica las premisas de Gustave Le Bon, ese "Bossuet de la sociología" ([1908] 1978, p. 7)],y el orden eurocentrista construidos desde la etnología "sin fundamento científico" ([1908] 1978, p. 9)], y que sirven de pilares de proyectos imperiales. Ironiza con la idea de "degeneración" de las razas manejada desde un ejercicio del poder europeo, particularmente del anglosajón. Asimismo, deja oír su voz de indignación ante la suerte que corren los “indígenas" y clama por las condiciones de exacción y "servidumbre política” ([1908] 1978, p. 16)] bajo la Colonia y el régimen republicano. Propone ante esta situación intolerable "la escuela y el pan" ([1908] 1978, p. 18)] y prefigura una rebelión de "indios", un acto de "virilidad" que, a la violencia de los gamonales, del gobierno central y el montonero "respondería con la violencia" ([1908] 1978, p. 19)].

A la denuncia de González Prada, el marxista José Carlos Mariátegui añade una visión materialista de la historia para entender la condición del "indígena” en las primeras décadas del siglo XX. Mariátegui antepone a las consideraciones de orden "moral" una reflexión en torno al régimen de propiedad de la tierra en el que 
predomina la hacienda, lo que explica, en amplias regiones de la sierra, el desarrollo trunco de las fuerzas productivas, que se mantenían en un estadio premoderno. En pocas palabras, el sistema de hacienda se nutre de las relaciones de servidumbre "indígena" mientras que la gran propiedad agraria en la costa es tributaria de la expansión del capital internacional. La semifeudalidad en la sierra, el dominio del capital financiero en la costa y el surgimiento de enclaves son caras de la misma moneda: un Estado que no ejerce un control directo sobre el territorio y un poder político concentrado en grupos oligárquicos y caciques locales, todo lo cual hace inviable cualquier proyecto de democracia liberal.

Mariátegui imagina al "indígena" con una vocación natural por el trabajo de la tierra: "una raza de costumbre y de alma agrarias" (2007, p. 47). Si por la acción de un vigoroso capitalismo de corte liberal se hubiese despojado a las comunidades de sus tierras y los campesinos se hubieran convertido en asalariados, se les habría abierto la posibilidad de militar en organizaciones clasistas y acceder a formas de lucha en alianza con otros proletarios; sin embargo, en su ser íntimo, esos "indígenas" se habrían "desnaturalizado un poco", señala Mariátegui (2007, p. 77), no sin cierto pesar.

Cuestiona, además, la demarcación territorial republicana (departamentos), que responde a un criterio "funcional" del centralismo limeño antes que a un reflejo de las realidades "regionales" y las agendas locales: "El departamento es un término político que no designa una realidad y menos aún una unidad económica e histórica" (2007, p. 203). Se trataría de un orden configurado en función de intereses exógenos a las regiones.

El movimiento indigenista que se desarrolla en esos años se suma al esfuerzo por desmontar la retórica racializante. Señala Obregón (2019) que, desde la Asociación Pro-Indígena, germina un proyecto político antirracista. Sus fundadores, Pedro Zulen, Dora Mayer y Joaquín Capelo, se conciben como aliados de los "indígenas"; proponen su emancipación por medio de la educación: la implantación de escuelas para las niñas y niños "indígenas", incluso dentro de las haciendas (Heilman, 2018). La Asociación promoverá, además, el disciplinamiento ciudadano de los pueblos, censurando las fiestas patronales en las que estos se "abandonaban" al alcoholismo. La emancipación imaginada por el indigenismo traía también una fuerte carga normativa y un afán civilizatorio.

En los indigenistas se advierte una sentida preocupación por la condición del "indígena” y determinación por impulsar el tránsito a la modernidad. Pero estos discursos no escapan a las relaciones de poder y reacomodo entre las élites limeñas y andinas; es decir, que no sólo intentan encontrar "un lugar" para el "indígena" en la nación del "mañana" sino también el "lugar" de la propia élite andina, que pretende legitimar su condición de clase dirigente e intermediaria entre la "masa indígena” y la distante élite capitalina.

Así, el orden imaginado de los indigenistas cusqueños, advierte de la Cadena, supuso "tanto un rechazo categórico al determinismo biológico como una naturalización de las jerarquias ${ }^{15}$ que, al menos nominalmente, provenían de diferencias morales/ culturales esenciales" (2004, p. 25). Las diferencias culturales que se van a naturalizar en el discurso sobre las "razas" serán el resultado de las desigualdades en la educación y la "decencia" social, por sobre los rasgos fenotípicos (lo biológico), sin que por esto el color de la piel deje de funcionar como un marcador social sobreentendido, del que se habla sólo a media voz.

En definitiva, esos pueblos "indígenas" que viven en un estado "natural" vinculados a la tierra (Mariátegui) o sumergidos en un pasado "milenario" (Alayza y Paz Soldán) encontrarán una vía de redención en el empeño del Estado, de sociedades indigenistas o por la acción política de un proyecto revolucionario que los llevaría al pleno goce de sus derechos ciudadanos (acceso a la tierra) y a un punto civilizatorio por medio de la educación, que tiene un carácter moral, espiritual y cultural. Esa emancipación es, pues, un viaje desde un "atrás" hacia un "adelante".

No es difícil colegir cómo esta retórica germina en un orden republicano que concibe al "indígena" instalado en un territorio-limbo, una suerte de "nación aparte" (Nugent, 2016) del resto de los peruanos y que reposa, advierte Nugent "en la idea de una alteridad insalvable entre el mundo indígena, básicamente andino, y el mundo de la cultura criolla, concentrada en Lima, independientemente del lugar de nacimiento de sus defensores" (2016, p. 171). 
Las sublevaciones "indígenas" a lo largo del siglo XIX y en la primera mitad del siglo XX -que exigían superar los abusos y exacciones que padecían a manos de los poderes locales y estatal y el reconocimiento de la condición de "compatriotas"- serán reprimidas con violencia. ${ }^{16}$ Incorporar a comunidades quechuas y aimaras al estatus de contemporáneos demandaba recomponer el orden republicano: de uno estamental a otro de derechos ciudadanos. Una perspectiva intimidante, por distintas consideraciones: amenazaba un orden fiscal (tributo indígena) ${ }^{17}$ vigente hasta mediados del siglo XIX. Asimismo, un orden productivo (relaciones de servidumbre en la tierra, la ley de conscripción vial); un orden social (servicios de pongaje, yanaconaje); y un orden simbólico, que planteaba renegociar una horizontalidad en el mundo de las interacciones cotidianas, ahí donde toman cuerpo las identidades imaginadas (y la alteridad).

\section{LOS TERRITORIOS EN EL SISTEMA DE REFERENCIA DE COORDENADAS}

Los distintos territorios considerados en estas líneas, el político administrativo, el económico con sus flujos de intercambio, construyen una mirada de lo "cerca" y lo "lejos" respecto de centros hegemónicos. Esa mirada que percibe lo que está "lejos" es, como se ha dicho, topológica y moral: es una distancia física y es distancia respecto de la modernidad y el progreso. Un tercer territorio que se desprende de esta experiencia de lo "lejos" -que se construye a partir de un saber que se enuncia en Occidente, particularmente desde la antropología- es la representación de los pueblos "primitivos", aquellos instalados o suspendidos en un pasado que, en un símil geológico, tiene su locus en un estadio anterior temporal y espacial: en un "atrás” que es un "antes" respecto de un presente civilizado.

Se aprecian diferencias en las delimitaciones étnicas que realizan los viajeros e intelectuales de las élites y el propio Estado peruano; no son trazos fijos ni unívocos. En el censo nacional de 1940, se emplean categorías "raciales", por las que los "indios" y "blancos" de la sierra se definen con frecuencia, en el conteo oficial, en función de un indicador lingüístico: el dominio de la lengua castellana o de la quechua. Y una tercera categoría, el "mestizo" o sujeto indígena "amestizado", tiende a situarse en una zona de hibridez cultural, la de aquel que se mueve en ambos lados del trazo lingüístico, en virtud del dominio de ambas lenguas y su adaptación cultural al medio de la modernidad occidental.

El indigenista Uriel García avizora en la migración territorial y simbólica del "indígena" hacia la modernidad el surgimiento de un "indio" que "es culturalmente, un alma en vías de amestizamiento" (Zevallos, 2002, p. 68). José Carlos Mariátegui, en cambio, influido fuertemente por otro notable indigenista, Luis E. Valcárcel -que proponía un proceso de "indigenización” de la sociedad peruana (López, 2018)-, no comparte el entusiasmo por un proyecto de "amestizamiento"; antes bien, insiste en el carácter nacional de "dualidad de raza, de lengua, de sentimiento, nacida con la invasión y conquista" (2007, p. 206).

Proponemos en este artículo que en la mirada de las élites, el sujeto "cholo" o "mestizo" se mueve en un campo semántico ancho, diverso y poroso, que abarca a los "indígenas" que migran a los centros urbanos (amestizados), a los sujetos fenotípicamente mestizos, y eventualmente, además, a sujetos "provincianos" (que provienen de una territorialidad "alejada"); en esta mirada de lo "cholo" o lo "mestizo" también inciden otros marcadores jerárquicos: clase social, estatus económico, género y otros.

Respecto del "ser indígena", nos encontramos ante representaciones no menos complejas. De ahí las comillas empleadas en este trabajo, pues se trata de contenidos en permanente disputa y negociación. Siguiendo a Wimmer (2008), el ámbito relacional es primordial en el trazado de la frontera étnica. Sobre un sustrato "racial" (biológico y especialmente fenotípico), la delimitación resulta de elementos estructurales y de otros, contingentes. En la sociedad peruana, la ubicación del "otro" se produce en un juego de poder y de relacionamiento social. Lo "indígena" es un concepto semántico y es un sentimiento en el ámbito de las interacciones. Funciona parcialmente como un hiperónimo: los pueblos quechuas que hacen de hipónimos ingresan en lo "indígena" mas no se agotan en ello y más bien lo rebasan contingentemente. Así, hemos 
visto, los quechuas que, siempre desde la perspectiva de las élites y del Estado, "caen" usualmente dentro de la categoría "indígena" eventualmente desbordaban sus límites étnicos y devienen, no sin ambigüedad, en "mestizos" culturales, moradores de las ciudades.

Proponemos una tipología de la experiencia de los territorios desde las élites, a partir de un sistema de coordenadas en un plano bidimensional, donde $\mathrm{E}$ es la recta del espacio y $\mathrm{T}$, la recta del tiempo imaginado. Así, desde la mirada de la élite huamanguina, su propia ubicación está en un "aquí" y en un "ahora", que es el punto de confluencia de las rectas E, T (0). Eventualmente, espacios de modernidad, como la ciudad de Lima, se encontrarían en un punto de convergencia $\mathrm{E}+\mathrm{x}, \mathrm{T}+\mathrm{x}$. Los pueblos quechuas se representan en puntos de convergencia dispersos en un espacio delimitado por valores - $\mathrm{E}$ y - T, donde la puna es un espectro que abarca posiciones dispersas, con valores negativos máximos -y; los "indígenas" que habitan las ciudades, en cambio, ocuparían posiciones expresadas en valores negativos mínimos. La educación llevaría a ciertos "indígenas", en el imaginario de ciertas élites, a posiciones con valores negativos mínimos. Mientras que las élites criollas o fenotípicamente "mestizas" del sur ayacuchano se ubicarían en puntos de confluencia E- y T- pero, por lo general, con valores más cercanos a 0 respecto de cualquier punto de "localización” "indígena”. Con la salvedad de que estas élites, en la medida en que logren consolidar vínculos con la modernidad alternativos al centro huamanguino (dueños de casas comerciales en Coracora, senadores de la República residentes en Lima, etc.), podrían ubicarse en puntos cercanos a 0 , en $0 \mathrm{o}$, excepcionalmente, en un punto de confluencia $\mathrm{E}+, \mathrm{T}+$, cercano a 0 , siempre desde la mirada de las élites huamanguinas.

Gráfico 1. Los sujetos ayacuchanos: territorios espaciales y temporales

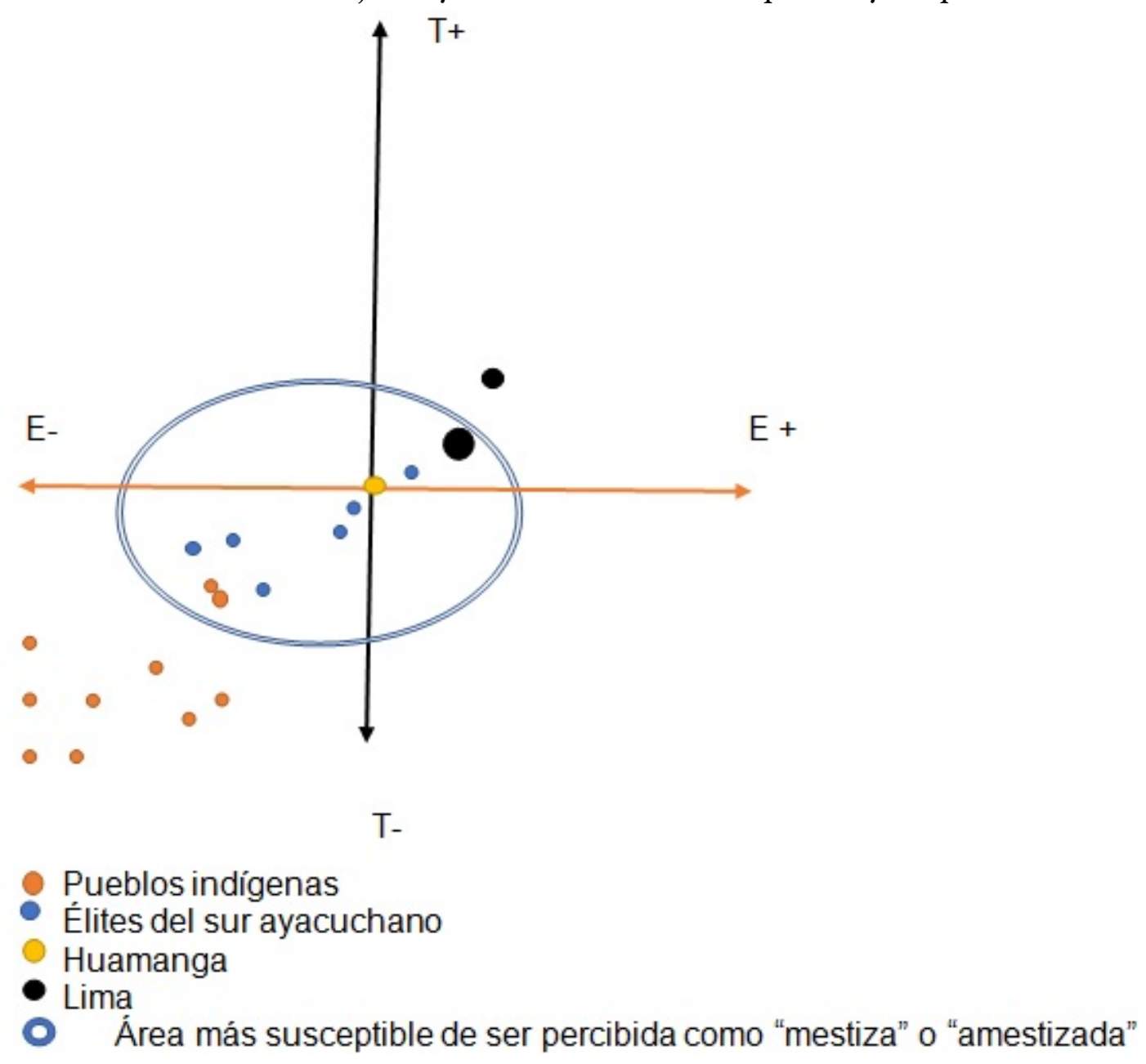

Elaboración propia 
Los "mestizos" quedarían dentro de un espacio fluido y permeable, delimitado por un círculo azul de línea discontinua, fisuras del "ser mestizo" en las que se registran entradas y salidas del campo semántico; en tanto frontera étnica, es también relacional. El constructo "ser mestizo" se concibe como "raza" (biología) aunque el elemento que define en última instancia es "cultural" (la impronta civilizatoria que "sale" del territorio de lo atávico "indígena"). El "mestizo" irrumpe, por decirlo así, en el espacio "indígena” y coincide, eventualmente, con la descripción fenotípica de las élites ayacuchanas y, en menor medida, de las limeñas. Hay que advertir, sin embargo, que esta territorialidad "mestiza" no es un campo homogéneo ni horizontal; de la Cadena advierte que "la taxonomía derivada de una definición de raza que subordinaba el fenotipo era particularmente dúctil, en tanto incluía al mismo tiempo una percepción de rígidas jerarquías” (2004, p. 26). Dicha territorialidad mantiene un orden de verticalidad sustantiva como sintaxis fundamental en las interacciones sociales.

\section{Conclusiones}

El territorio político propone un orden administrativo que organiza la vida de los ayacuchanos. El relato histórico promovido desde el Estado nutre la idea de una sociedad ayacuchana, cuyos miembros compartirían vínculos históricos (de un "atrás" construido a posteriori), propiciando cierto sentimiento de pertenencia dentro de un orden estamental. El territorio devendría entonces en un cuerpo, con un centro visible, Huamanga.

Desde finales del siglo XIX, la articulación del territorio político desde Huamanga se ve amenazada con los flujos de intercambio hacia Lima, Arequipa y Huancayo, que configuran territorios económicos locales centrífugos.

A la desarticulación del territorio huamanguino se suma el desencuentro en una otra territorialidad, la del orden de las "razas" en el Ayacucho de principios del siglo XX. Emitido desde la posición de las élites, expone una comunidad fracturada, es decir, vinculada con ciertos lazos emocionales que la proyectan al pasado pero ante la imposibilidad de convivir en el horizonte común, que es el tiempo presente: atrapada en el oxímoron de construir lo que se encuentra separado por distancias ontológicas, temporal-espaciales.

La tipología propuesta (Gráfico 1) del lugar de las poblaciones en el orden administrativo ayacuchano y en las representaciones de las "razas" de principios del siglo XX permite visualizar una topografía (¿dónde están?) y una ontología (¿qué son?) de los sujetos sociales; asimismo, imaginar la distancia que separa a unos sujetos quechuas "arcaicos" (o arcaizados en el discurso) del lugar excluyente y horizontal que ocupan los “contemporáneos".

\section{REFERENCIAS}

Altschuler, B. (2013). Territorio y desarrollo: aportes de la geografía y otras disciplinas para repensarlos. Theomai, 27-28. Recuperado de https://www.redalyc.org/pdf/124/12429901005.pdf

Arca Parró, A. (1923). ¿Dónde vivían los Chancas? Revista Inca, 1(4), 971-974.

Arroyo, S. (2003). Julio C. Tello y la antropología. Investigaciones Sociales, 11, 123-149. Universidad Nacional Mayor de San Marcos. Recuperado de https://revistasinvestigacion.unmsm.edu.pe/index.php/sociales/article/downlo $\mathrm{ad} / 8108 / 7075 /$

Basadre, J. (1969). Historia de la República del Perú.Vol. 9. Lima: Editorial Universitaria.

Blanco, J. (2007). Espacio y territorio: elementos teórico-conceptuales implicados en el análisis geográfico. En M. V. Fernández y R. Gurevich (Coords.). Geografia. Nuevos temas, nuevas preguntas (pp. 37-64). Buenos Aires: 
Biblos. Recuperado de http://www.scba.gov.ar/includes/descarga.asp?id=21382\&n=Espacio\%20y\%20territor io\%20Blanco.pdf

Burga, M. y Reátegui, W. (1981). Lanas y capital mercantil en el sur. La casa Ricketts, 1895-1935. IEP.

Canales, P. y Franco, J. (2019). No apuesto a humo de paja. Memorias de Ayacucho sur. Lima:Ediciones Capazul.

Cerna, J. (2019). Términos quechuas, quechuismos y arcaísmos castellanos en la poesía de Mario Florián. Perspectiva 20(1), 97-111.

Choque, D. (2018). La revuelta campesina de Oyolo de 1876. Texto inédito.

Contreras, C. (2005). El impuesto de la contribución personal en el Perú del siglo XIX. Histórica, 29(2), 67-106.

Contreras, C. y Díaz, A. (2008). Los intentos de reflotamiento de la mina de azogue de Huancavelica en el siglo XIX. América Latina en la Historia Económica 29, 5-29. Recuperado de http://www.scielo.org.mx/scielo.php?script $=$ sci_arttext\&pid=S1405-22532008000100001

Dantier, B. (2002). Introduction à la psychologie des foules de Gustave Le Bon. Chicoutimi: Université du Québec à Chicoutimi. Recuperado de https://psychaanalyse.com/pdf/introduction_a_la_psychologie_des_foules.pdf.

Degregori, C. I. (1978). Indigenismo, clases sociales y problema nacional. Lima: Centro Latinoamericano de Trabajo Social.

De la Cadena, M. (2004). Indígenas y mestizos. Lima: IEP. Recuperado de https://bityl.co/8Kar

Del Águila, A. (2013). La ciudadanía corporativa. Política, constituciones y sufragio en el Perú (1821-1896). Lima: IEP.

Del Pino, P. (2017). En nombre del gobierno. El Perú y Uchuraccay: un siglo de política campesina. Lima: La Siniestra.

Díaz Martínez, A. (1968). Cangallo, latifundio y comunidad. Huamanga: Universidad Nacional San Cristóbal de Huamanga.

Drinot, P. (2018). La Patria Nueva: Economia, sociedad y cultura en el Perú, 1919-1930. Chapel Hill: The University of North Carolina Press.

Fabian, J. (2014). Time and the Other. How Anthropology Makes its Object. Nueva York: Columbia University Press.

Ferguson, J. \& Gupta, A. (2002). Spatializing states: toward an ethnography of neoliberal governmentality. American Ethnologist 29 (4), 981-1002. Recuperado de https://www.uio.no/studier/emner/sv/sai/SOSANT2220/h12/ Ferguson\%20and\%20Gupta\%202002\%20Spatializing\%20States.pdf

Fernandes B. M. (2006). Movimientos socioterritoriales y movimientos socioespaciales Contribución teórica para una lectura geográfica de los movimientos sociales. Alicante: Universidad de Alicante. Recuperado de https://web.ua. es/en/giecryal/documentos/documentos839/docs/bmfunesp-5.pdf

Fernandes, B. M. (2008). Sobre la tipología de los territorios. Alicante: Universidad de Alicante. Recuperado de http:/ /web.ua.es/es/giecryal/documentos/documentos839/docs/bernardo-tipologia-de-territorios-espanol.pdf

Flores Galindo, A. y Burga, M. (1984). Apogeo y crisis de la República Aristocrática. Lima: Rikchay Perú.

Giraldo, M. y Liria Franch, A. (1979). Hacienda y gamonalismo: Azángaro, 1850-1920. (Tesis de maestría). Pontificia Universidad Católica del Perú, Lima, Perú.

Glave, L. M. y Urrutia, J. (2000). Radicalismo político en élites regionales: Ayacucho 1930-1956. Debate Agrario, 31, $1-37$.

González Prada, M. (1978) [1908]. Nuestros indios. México D.F.: Universidad Nacional Autónoma de México. Recuperado de http://ru.ffyl.unam.mx/bitstream/handle/10391/2973/29_CCLat_1978_Gonzalez_Prada.pd f? sequence $=1$

Gonza, A. (2020). Discurso y política indígena en el Oncenio de Leguía. Espiral, 2(3), 69 - 76. Recuperado de http: //dx.doi.org/10.15381/espiral.v2i3.17731

Guevara, V. (1927). El problema indígena. La Sierra 1(6), 2-5.

Heilman, J. (2018). Rebeliones inconclusas. Ayacucho antes de Sendero Luminoso. Lima: La Siniestra.

Hildebrandt, M. (1994). Peruanismos. Lima: Biblioteca Nacional del Perú.

Hirsch, E. (2008). Pueblo indio. La religión y el discurso del progreso en el valle del Colca. Proyecto de estudio independiente. School for International Training, Cusco, Perú. 
INEI (1944). Censo Nacional de Población y Ocupación, 1940. Departamento de Ayacucho. Dirección Nacional de Estadística.

Jong, G. (2001). Introducción al método regional. LIPAT. Recuperado de https://www.gdejong.com.ar/docs/libros/I ntroduccion_Metodo_Regional_1.pdf.

Le Bon, G. (1895). Lois psychologiques de l'évolution des peuples. Université du Québec à Chicoutimi. Recuperado de http://classiques.uqac.ca/classiques/le_bon_gustave/lois_psycho_evolution_peuples/le_bon_lois_psycho.pdf

López, P. (2018). Tempestad en los Andes de Luis E. Valcárcel o el despertar del alma inca. Babel (38). Recuperado de http://journals.openedition.org/babel/6021

Llanos-Hernández, L. (2010). El concepto del territorio y la investigación en las ciencias sociales. Agricultura, Sociedad y Desarrollo, 7(3). Recuperado de http://www.scielo.org.mx/scielo.php?script=sci_arttext\&pid=S1870-54722 010000300001.

Manrique, N. (1988). Yawar Mayu. Sociedades terratenientes serranas, 1879-1910. Lima: IFEA.

Mariátegui, J.C. (2007) [1928]. 7 Ensayos de interpretación de la realidad peruana. Lima: Minerva.

McEvoy, C. (2019). En pos de la República: ensayos de historia politica e intelectual. Lima: IEP.

Méndez, C. (2000). Incas sí, indios no. Apuntes para el estudio del nacionalismo criollo en el Perú. Documento de trabajo n. ${ }^{\circ}$ 56. Lima: IEP. Recuperado de http://repositorio.iep.org.pe/bitstream/handle/IEP/865/Mendez_Incas-si-i ndios-no.pdf?sequence $=2 \&$ isAllowed $=y$

Monografía de la provincia de Parinacochas (1950). Vol. 1. Lima: Editorial Para Todo.

Montesquieu, Ch-L. (2018). El espiritu de las leyes. México D.F.: Partido de la Revolución Democrática. Recuperado de https://www.prd.org.mx/libros/documentos/libros/espiritu-leyes.pdf

Navarro del Águila, V. (1939). Las tribus de Ankcu Wallokc. Cusco: H.G. Rozas Sucesores,

Obregón, W. (2019). El porvenir de las razas: el racialismo en el Perú entre los siglos XIX y XX. Análisis, 51(94), 81-100. Recuperado de https://revistas.usantotomas.edu.co/index.php/analisis/article/view/4255/pdf

Nugent, G. (2016). Errados y errantes. Modos de comunicación en la cultura peruana. Lima: La Siniestra.

Palma, C. (1897). El porvenir de las razas en el Perú (Tesis de bachillerato). Universidad Nacional Mayor de San Marcos, Lima, Perú. Recuperada de https://cybertesis.unmsm.edu.pe/bitstream/handle/20.500.12672/338/Pa lma_cl.pdf?sequence $=1$ \&isAllowed $=y$

Pereyra, N. (2019). Campesinos republicanos: la sociedad rural de Ayacucho y el estado peruano en el siglo XIX (1840-1880) (Tesis de doctorado). Pontificia Universidad Católica del Perú, Lima, Perú. Recuperada de https: //tesis.pucp.edu.pe/repositorio/handle/20.500.12404/16644

Renan, E. (1871). La réforme intellectuelle et morale. París : Biblioteca Nacional de Francia. Recuperado de https://g allica.bnf.fr/ark:/12148/btv1b86267612.texteImage.

Rojas, N. (2010). El mito del progreso en Ayacucho: 1900-1950 (Tesis de maestría). Universidad Nacional San Cristóbal de Huamanga, Ayacucho, Perú.

Silva, F. (2021). Comunicación personal.

Urquiaga, J. (1977) [1916]. Indios. En Seminario de Historia Rural Andina, Lima, Universidad Nacional Mayor de San Marcos, Perú. Recuperado de http://fondoeditorial.unmsm.edu.pe/index.php/fondoeditorial/catalog/vie w/266/246/1069-1

Valdizán, H. (1924). La alienación mental en la raza india. Lima: Universidad Nacional Mayor de San Marcos. Recuperado de https://revistasinvestigacion.unmsm.edu.pe/index.php/anales/article/view/10229

Wimmer, A. (2008). The Making and Unmaking of Ethnic Boundaries: A Multilevel Process Theory. American Journal of Sociology 113(4), 970-1022.

Zapata, A., Rojas R. y Pereyra N. (2008). Historia y cultura de Ayacucho. Lima: UNICEF-IEP. 


\section{Notas}

1 Actualmente, la capital del departamento de Ayacucho se denomina indistintamente Huamanga o Ayacucho. Por claridad expositiva, la capital del departamento aquí se denomina Huamanga.

2 Según M. Hildebrandt, el término "gamonal”, que en países de la Comunidad Andina y América Central significa "cacique de pueblo" o "persona influyente", en el Perú adquirió un sentido marcadamente negativo, entendiéndose como "terrateniente que explota al indígena" (1994).

3 Sobre el sistema de haciendas y las relaciones de servidumbre en el sur andino de principios del siglo XX, véanse Manrique (1988), Flores Galindo y Burga (1984), Giraldo y Liria Franch (1979), Degregori (1978), Urquiaga (1977), Basadre (1969), Díaz Martínez (1968), Mariátegui (2007) [1928], Guevara (1927).

4 Derivación del vocablo quechua "punku" (puerta), por metonimia, el sirviente apostado detrás de la puerta. Se denominaba "pongaje" al servicio doméstico que indígenas de comunidades mantenían por turnos y como "obligación” en casa del hacendado.

5 En este trabajo, se sostiene que el concepto semántico "indígena” es un territorio en disputa, con una base racial, sin duda, y también fluida y relacional; es decir, no responde a categorías rígidamente adscriptas. De ahí el uso de las comillas. En este artículo se discutirá el trazado de dicha frontera étnica.

6 El vocablo "misti" es un término quechua que provendría del castellano "mestizo". En la definición de Jacinto Cerna Cabrera, "Dicho de una persona: Nacida de padre y madre de raza diferente, en especial de hombre blanco e india, o de indio y mujer blanca" (2019, p. 105). Por extensión, en el sur andino se denominaba así a los "notables" de un pueblo o ciudad.

7 La exaltación del pasado prehispánico en el Perú por parte de las élites del siglo XIX y XX convive con una mirada peyorativa hacia el indígena contemporáneo. La historiadora C. Méndez lo expresa de forma paradigmática: "Incas sí, indios no", y agrega: "Pero esta retórica de glorificación del pasado inca apropiada por los criollos convivía con una valoración despreciativa del indio (o lo que por tal se tuviera) en el presente” (2000). Para el caso ayacuchano, la retórica se construye con relatos del pasado de pueblos preincas.

8 La cursiva es nuestra.

9 La cursiva es nuestra.

10 La cursiva es nuestra.

11 La cursiva es nuestra.

12 La cursiva es nuestra.

13 La cursiva es nuestra.

14 Hubo que esperar a la ley de Reforma Agraria de 1969 para terminar con las relaciones de servidumbre; a la Constitución de 1979, para admitir el derecho al voto de los analfabetos, de mayoría indígena.

15 La cursiva es nuestra.

16 Las sublevaciones indígenas contra el orden republicano arrecian desde finales del siglo XIX, coincidiendo con el proceso de concentración de la tierra, a manos de terratenientes del sur andino. Entre las sublevaciones se destaca la de campesinos indígenas en Huancané (Puno), encabezada por el mestizo Juan Bustamante, que se saldaría con la masacre de Pusi (1868). "Mi lema y mi programa son que los indios no sean excluidos de los beneficios sociales que la esplendente independencia del Perú prodiga a los blancos”, proclamó el líder indigenista (McEvoy, 2019, p. 229).

17 La contribución personal, que fue un impuesto indígena, se mantendrá con modificaciones hasta 1895 (Contreras, 2005). Será, por mucho tiempo, una de las principales fuentes de ingreso del Estado peruano. 